\title{
Računalniška emulacija kot strategija digitalnega ohranjanja računalniških sistemov in programske opreme
}

Jurij Miheličำ, Mojca Ferle ${ }^{2}$

${ }^{1}$ Fakulteta za računalništvo in informatiko, Univerza v Ljubljani, Večna pot 113, 1000 Ljubljana ${ }^{2}$ Mestni muzej Ljubljana, Muzej in galerije mesta Ljubljane, Gosposka 15, 1000 Ljubljana jurij.mihelic@fri.uni-lj.si, mojca.ferle@mgml.si

\section{Izvleček}

Z razvojem in vzponom področij kot so elektrotehnika, računalništvo ter informatika je vzniklo tudi področje digitalnega ohranjanja, ki se ukvarja z ohranjanjem digitalnih artefaktov. Zaradi interdisciplinarnosti področja in širokega nabora pristopov, katerih sistematičen pregled podamo v prvem delu članka, se v osrednjem delu članka osredotočimo predvsem na računalniško emulacijo, ki skupaj z muzejskim pristopom nudi enovit pristop k digitalnemu ohranjanju. Glavni namen članka je opisati metode, pristope, tehnike in izkušnje, ki smo jih pridobili z digitalnim ohranjanjem slovenske računalniške zapuščine in izvedbe emulatorjev dveh starodobnih računalnikov. Poleg emulacije procesorja in naprav so za digitalno ohranjanje računalniških sistemov pomembni tudi drugi vidiki ohranjanja, kot sta emulacija okolja in integracija z gostiteljem. V članku podamo sistematičen pregled ohranitvenih vidikov emulacije skupaj s sistemskimi tehnikami za njihovo izvedbo.

Ključne besede: digitalno ohranjanje, digitalni artefakt, muzejski pristop, računalniška emulacija

\section{Abstract}

Due to the development and rise of areas such as electrical engineering, computer science and informatics, the area of digital preservation has also emerged the main focus of which is the preservation of digital artifacts. In the first part of the article, we give a systematic review of a wide range of approaches to digital preservation, followed by the main contribution which focuses mainly on computer emulation which accompanied, with the museum approach, offers a unified and complete approach to digital preservation. The main purpose of the article is to describe the methods, approaches, techniques and experiences gained by the digital preservation of Slovenian computer legacy and implementations of emulators of two rare retro computers. In addition to processor and device emulation, other aspects of preservation, such as environment emulation and host integration, are also important for the digital preservation of computer systems. The article provides a systematic overview of the preservation aspects of emulations together with system techniques for their implementation.

Keywords: Digital preservation, digital artefact, musealization, computer emulation

\section{UVOD}

Človek, kot del družbe, praktično že od svojih začetkov na takšen ali drugačen način obdeluje informacije, jih ustvarja, hrani in deli z drugimi. Večina informacij je bila še pred nekaj desetletji ustvarjena in zapisana na papir, danes pa je nenehen in hiter razvoj informacijske tehnologije močno spremenil tisočletja uveljavljeno prakso, saj večina informacij nastane in je zapisana neposredno $v$ digitalni obliki.

Posledice razvoja so nova znanja, odkritja, izbolj- šave, inovacije in izdelki, ki pogosto hitro prodrejo tako v vsakdanja življenja ljudi kot tudi gospodarske dejavnosti, še hitreje pa zastarajo in posledično izgubijo na gospodarski in ekonomski pomembnosti. S tem pa neredko pridobijo kulturno vrednost in postanejo del kulturne dediščine, s čimer se odpira nov izziv njihove ohranitve v ustrezni obliki, ki omogoča njihov nadaljnji dostop.

Ohranjanje je uveljavljena družbena dejavnost, s katero se navadno ukvarjajo ustanove, kot so knjižni- 
ce, arhivi, galerije in muzeji, njen glavni namen je zagotavljanje dolgoročne javne dostopnosti in uporabnosti objektov (tudi artefaktov) ohranjanja. Objekt zanimanja je lahko kar koli (npr. knjiga, slika, orodje), le da nosi neko kulturno, družbeno ali drugo vrednost.

Kadar gre pri dejavnosti ohranjanja za digitalne artefakte oz. informacije (npr. programska in strojna oprema), področju pravimo digitalno ohranjanje. Pri tem je pomembno poudariti razliko med digitalnim ohranjanjem in digitalizacijo $\mathrm{v}$ osnovi nedigitalnih podatkov $\mathrm{z}$ namenom njihovega ohranjanja, pri čemer slednje lahko naknadno povzroči potrebo po digitalnem ohranjanju. Z drugimi besedami, digitalno ohranjanje se osredotoča na digitalne artefakte, tako izvorno digitalne (angl. born-digital) kot digitalizirane. $\mathrm{V}$ nasprotju $\mathrm{z}$ nedigitalnimi podatki, za katere je dokaj jasno, v čigavi odgovornosti je njihovo ohranjanje (npr. nacionalne knjižnice), pa temu ni tako za digitalne podatke.

Razlog za razvoj novonastalega področja se vsekakor skriva $\mathrm{v}$ že omenjenem hitrem razvoju informacijske tehnologije; posledično pa tudi njenem hitrem zastaranju, saj npr. pomnilni mediji, podatkovni formati, strojna in programska oprema, s časom hitro postanejo zastareli in redko uporabljani v praksi. Digitalno ohranjanje je izredno interdisciplinarno področje, ki zajema vede in znanosti od arhivistike, dokumentalistike, knjižničarstva, muzeologije preko upravljanja informacij in znanja, semantičnih tehnologij, podatkovnih baz, sistemske programske opreme, elektrotehnike do upravljanja digitalnih pravic, varnosti, zakonodaje, psihologije in biologije. Pomembnosti področja se zavedata tudi Evropska komisija in Ministrstvo za kulturo Republike Slovenije, ki v okviru digitalne agende želita spodbuditi evropski digitalni potencial [Ministrstvo za kulturo Republike Slovenije, 2013].

$Z$ razmahom Interneta in svetovnega spleta se pojavlja vse več izvorno digitalnih vsebin kot so spletne strani, fotografije, avdio in video vsebine, podatkovne zbirke ipd. Za mnoge izmed teh vsebin je $\mathrm{z}$ vidika digitalne ohranitve poskrbljeno s strani Internetnega arhiva ${ }^{1}$. Kljub temu pa nekatere izmed njih predstavljajo, zaradi hrambe $\mathrm{v}$ zapletenih oblikah in formatih, še posebej trd oreh za digitalno ohranjanje, sem sodijo npr. interaktivne spletne strani, igričarska okolja, družbena omrežja in programska oprema.
Digitalni objekti z vidika ohranjanja niso samostojni oz. neodvisni. Za njihovo ohranitev in ustrezno upodabljanje moramo pogosto ohraniti še okolje, v katerem obstajajo, npr. tako pripadajočo strojno kot programsko opremo. Slednja je tipičen primer, katere format hrambe močno vpliva na pristop $\mathrm{k}$ njenemu ohranjanju. Če je hranjena v obliki izvorne programske kode in je na voljo ustrezen prevajalnik za novejšo izvajalno platformo, potem je ohranjanje lahko relativno preprosto. Če pa gre za strojno kodo za zastarelo izvajalno platformo, pa je njeno ohranjanje lahko izredno velik izziv, saj je treba ohraniti tudi samo platformo. Dober primer tega je ohranjanje retro računalniških iger za zastarele igralne konzole in računalnike, kjer je treba zagotoviti še ohranitev ustreznega izvajalnega okolja, operacijskega sistema, samega računalnika in morebitnih pripadajočih naprav.

V tem članku usmerimo pozornost $\mathrm{k}$ digitalnemu ohranjanju računalniških sistemov, strojne in programske opreme. Izmed različnih pristopov k reševanju tega izziva se podrobneje lotimo emulacije, ki je sicer inženirsko gledano dokaj zahtevna, vendar po vloženem začetnem trudu nudi celovito rešitev. Naše izkušnje, predstavljene $\mathrm{v}$ tem članku, temeljijo na raziskovanju virov, dokumentacije, načrtovanju in izvedbi emulatorjev [Horvat in Mihelič, 2018] za dva starodobna računalnika slovenske izdelave (Iskra Delta Partner in Gorenje Dialog), poleg tega pa tudi na rezultatih ${ }^{2}$ izvedbe projekta $S l o R_{a D e}{ }^{3}$, v okviru katerega so študentje različnih usmeritev raziskovali ozadje in zgodovino slovenske računalniške dediščine. Zgodovinski pogled na podjetje Iskra Delta se nahaja v npr. [Bufon, 2018, Škrubej, 2008].

$S$ tem člankom želimo zadostiti več ciljem. Osnovni in splošni cilj prispevka je predstavitev področja digitalnega ohranjanja, opredelitev pojma digitalnega artefakta ter opis taksonomije pristopov $\mathrm{k}$ digitalnemu ohranjanju. Glavni cilj članka je predstavitev emulacije kot pristopa $\mathrm{k}$ digitalnemu ohranjanju, pri čemer se na celovit način osredotočimo predvsem na ohranitvene vidike emulacije, probleme, težave in izzive, ki se pojavljajo pri njeni izvedbi. Osnovnemu cilju članka metodološko zadostimo preko pregleda splošne literature o emulaciji in digitalnem ohranjanju. Pregled ohranitvenih vidikov pa temelji pred- 
vsem na obstoječih izkušnjah z izvedbo zgoraj naštetih projektov. Primerjava tehnik in analiza pristopov je zaradi narave področja predvsem kvalitativna.

V naslednjem razdelku opišemo področje digitalnega ohranjanja, podamo njegove osnovne smernice, predstavimo različne poglede na digitalne artefakte in pristope za digitalno ohranjanje. V tretjem razdelku opišemo muzejski pristop, njegovo vlogo in proces muzealizacije. Glavni razdelek članka je četrti, v katerem se podrobneje lotimo emulacije kot pristopa $\mathrm{k}$ digitalnemu ohranjanju artefaktov, opišemo naše izkušnje s tem pristopom pri digitalnem ohranjanju slovenskih starodobnih računalnikov. V zadnjem poglavju zaključimo članek.

\section{DIGITALNO OHRANJANJE}

$\mathrm{V}$ tem razdelku najprej predstavimo digitalno ohranjanje, njegovo strateško vlogo v družbi, osredotočimo se na pregled oblik digitalnih artefaktov in naštejemo pristope $\mathrm{k}$ digitalnemu ohranjanju.

\subsection{Strategija digitalnega ohranjanja}

Pomembnost digitalnega ohranjanja je $\mathrm{v}$ sodobni družbi že zaznana, v nedavni preteklosti je bilo zagnanih že več pobud za njeno vzpodbujanje, med drugim tudi v okviru zadnjih nekaj evropskih programov za raziskave in tehnološki razvoj. Primer dobrih praks so predstavljeni v [Strodl et al., 2007] s poudarkom na oblikovanju strategije in načrtovanju ohranitvenih dejavnosti.

Ameriška neprofitna organizacija Online Computer Library Center je leta 2006 definirala strategijo [Online Computer Library Center, 2006] dolgotrajnega ohranjanja digitalnih objektov, ki nudi več od dobrega sistema za varnostno kopiranje. Strategijo grafično ponazorimo s piramidno shemo, predstavljeno na sliki 1.

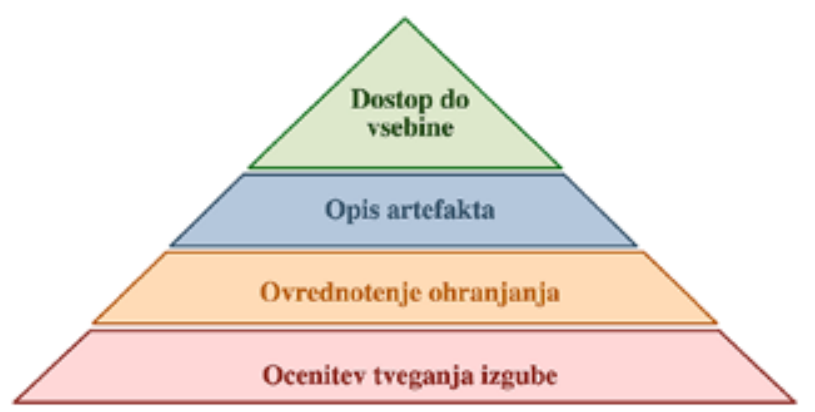

Slika 1: Primer različnih pogledov na digitalni artefakt
Strateška shema sestoji iz več slojev, pri čemer vsak sloj sloni na izbranem vidiku prizadevanja za digitalno ohranjanje. Odločitve na nekem sloju temeljijo na nižjih slojih, zato dejavnosti digitalnega ohranjanja potekajo po slojih od spodaj navzgor. Kratek opis posameznih slojev oz. prizadevanj je:

- ocenitev tveganja izgube artefakta oz. digitalne vsebine zaradi tehnoloških značilnosti, kot so npr. lastniški datotečni formati in programska oprema,

- ovrednotenje vsebine digitalnih objektov z vidika načinov in težavnosti pretvorbe formatov in drugih ohranitvenih dejavnosti,

- ugotavljanje primernih metapodatkov, potrebnih za vsako vrsto objekta in povezanosti z objekti,

- zagotavljanje dostopa do vsebine.

\subsection{Oblika digitalnih artefaktov}

Omenili smo že, da gre pri digitalnem ohranjanju predvsem za ohranjanje artefaktov, katerih narava je v osnovi digitalna, najsi bodo to izvorno digitalni ali naknadno digitalizirani nedigitalni (analogni) artefakti. Ne glede na izvor digitalnega artefakta, pa ločimo več pogledov na obliko, kako želimo ohraniti artefakt [Webb, 2003, Guttenbrunner, 2007].

- Fizična oblika Pri ohranjanju artefakta v fizični obliki gre za obravnavo izzivov, ki se nanašajo na fizikalne lastnosti objektov ohranjanja (npr. propadanje pomnilnih medijev).

- Logična oblika Zajema surove podatke (zaporedje bitov), ki jih artefakt fizično predstavlja, pri čemer imajo podatki navadno neko logično strukturo in obliko zapisa.

- Konceptualna oblika Obravnava dejanskega objekta, ki je shranjen, pri čemer je pomebna semantika samega objekta.

- Kontekstna oblika Ohranjanje konteksta, v katerem je bil ustvarjen digitalni artefakt. Kontekst se hrani v obliki metapodatkov kot dodaten dokument.

Kot primer različnih pogledov na digitalni artefakt si oglejmo sliko $2^{4}$, kjer a) fizično obliko digitalnega artefakta predstavlja pomnilni medij disketa, ki b) $\mathrm{z}$ vidika logične oblike hrani datoteko (datoteka

4 Vir slike pod a) je https://commons.wikimedia.org/wiki/File:Radio_Shack_TRS 80_Floppy_Disk.jpg, ostale slike so last avtorjev 


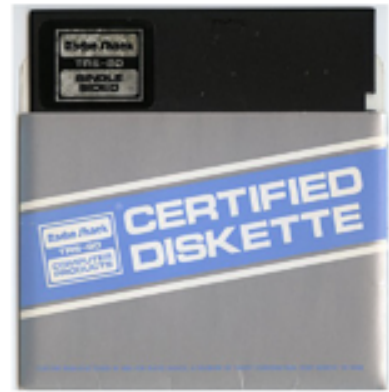

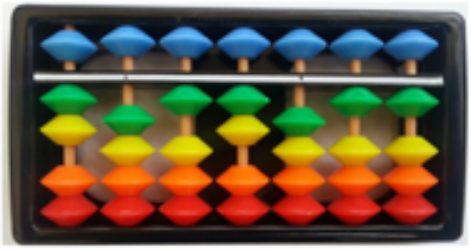

c) konceptualna oblika: slika
Vrsta datoteke: slika

Format: GIF

Različica: $89 a$

Dimenzija: 256 x 128

Vsebina: Soroban

d) kontekst: metapodatki

a) fizična oblika: disketa

\section{$00 \quad 4749463839610100 \quad 0100800000000000$ \\ 10 ffffff $21 \mathrm{f} 9040100 \quad 0000002 \mathrm{c} 00000000$ \\ $200100010000020144003 \mathrm{~b}$}

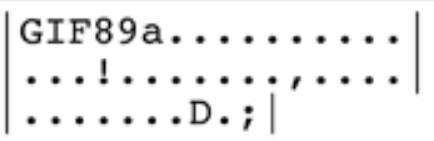

b) logična oblika: datoteka

Slika 2: Primer različnih pogledov na digitalni artefakt

je na sliki predstavljena kot šestnajstiški in tekstovni delni izpis njene vsebine), katere c) konceptualna vsebina je slika, katere d) kontekst je podan z metapodatki (metapodatki se hranijo v dokumentu, ki nastane $\mathrm{v}$ procesu muzealizacije).

\subsection{Pristopi digitalnega ohranjanja}

Za ohranjanje digitalnega artefakta v literaturi [Webb, 2003, Guttenbrunner, 2007] najdemo več pristopov in rešitev, ki jih naštejemo in na kratko predstavimo $\mathrm{v}$ naslednjem seznamu.

- Muzejski pristop Hranjenje izvorne strojne in programske opreme na ustrezen način $\mathrm{z}$ namenom ohranjanja njene javne dostopnosti.

- Analogna preobrazba Pretvorba digitalnih podatkov v nedigitalni format, ki ga je lažje dolgotrajno hraniti, npr. tiskanje na papir.

- Osveževanje oz. replikacija Prenos podatkov iz enega pomnilnega medija na drugega, pri čemer sta oba medija iste vrste.

- Migracija Prenos podatkov iz enega pomnilnega medija na drugega, pri čemer sta medija različne vrste, pri čemer je ciljni medij praviloma tehnološko sodobnejši.

- Preoblikovanje Pretvorba formata zapisa podatkov iz izvornega, starega formata v novega, sodobnejšega, ki omogoča nadaljnjo dostopnost artefakta.

- Uporaba standardov Zagotavljanje dolgotrajnega dostopa do artefakta preko uporabe odprtih, podprtih, dostopnih in dogovorjenih standardov (npr. datotečnih formatov) namesto zaprtih ali lastniških.

- Zagotavljanje kompatibilnosti Izvedba programske ali strojne opreme na način, da zagotavlja kompatibilnost s starejšimi različicami.

- Nadgraditev Nadgraditev in dopolnitev podatkov z meta podatki, dokumenti, programsko in strojno opremo, ki omogoča dostop do oz. pregled vsebine artefakta.

- Emulacija Izvedba nove programske opreme, ki oponaša izvorno programsko ali strojno opremo.

V praksi digitalno ohranjanje navadno izvedemo s kombinacijo več različnih pristopov. V tem članku se osredotočimo predvsem na emulacijo, ki skupaj z muzejskim pristopom nudi celovit pristop k digitalnemu ohranjanju.

\section{MUZEJSKI PRISTOP}

$\mathrm{V}$ tem razdelku predstavimo osnovno vlogo muzejev $\mathrm{v}$ družbi in sam proces muzealizacije, ki je pomemben tudi z vidika digitalnega ohranjanja.

\subsection{Vloga muzejev}

Muzeji kot osrednje ustanove za hranjenje premične kulturne dediščine, evidentirajo, zbirajo, dokumentirajo, vrednotijo, ohranjajo, interpretirajo, raziskujejo in predstavljajo snovno in nesnovno kulturno dediščino od prazgodovine do danes. V 90. letih 20. stoletja so računalniki v življenje ljudi vstopili skozi široko odprta vrata in danes si življenja brez njih ne more- 
mo več predstavljati. Postali so nepogrešljivo orodje v vsakdanjem življenju ljudi vseh generacij v delovnem in vedno bolj tudi prostem času. $Z$ vidika razvoja in uporabe $\mathrm{v}$ vsakdanjem življenju so tako računalniki postali tudi predmet zanimanja humanističnih, družboslovnih ved, med njimi tudi muzejske stroke.

Od začetnega bolj ali manj naključnega zbiranja (ohranjanje prvih računalnikov, strojne in programske opreme, ki so se uporabljali v muzejih) so se bolj sistematičnega zbiranja računalniške opreme lotili muzeji, ki se ukvarjajo tudi/ali z novejšo in sodobno zgodovino. Rezultat tega je bila prva pregledna razstava o razvoju računalnikov Goto 1982, ki so jo skupaj z Računalniškim muzejem idr. ustanovami in posamezniki pripravili v Muzeju novejše zgodovine Slovenije leta 2012 [Bezek et al., 2012]. Pomembno delo na tem področju opravlja tudi skupina zanesenjakov, organiziranih v Društvo računalniški muzej, ki se je že zgodaj zavedala tako pomembnosti dosežkov »slovenske računalniške industrije« kot tudi neomejenih možnosti uporabe. Zavidljiva zbirka počasi prerašča v slovenski računalniški muzej. ${ }^{5}$

$\mathrm{V}$ muzejih je računalniška oprema predmet zanimanja/zanimiva $z$ več zornih kotov:

- z vidika razvoja izvorne slovenske računalniške (strojne in programske) opreme; s tem tudi muzeji pripomorejo $h$ krepitvi zavedanja o pomembnosti le te, saj je v zlati dobi razvoja, v 70. in 80. letih 20. stoletja, slovensko računalniško inženirstvo šlo v korak z razvojem v svetu;

- z vidika vsesplošne uporabnosti, implementacije računalnikov in sodobne tehnologije $\mathrm{v}$ vse pore človekovega delovanja in življenja;

- kot uporabno delovno orodje za obdelavo muzejskih predmetov; sodelovanje muzejskih strokovnjakov pri razvoju aplikacij za obdelavo, muzealizacijo predmetov (prva slovenska muzejska aplikacija MODES [Simikič, 2002], danes so v uporabi Fundus [Knez, 2010], Galis in Kronos).

\subsection{Proces muzealizacije}

Poleg zbiranja predmetov/digitalnih artefaktov je ena osnovnih nalog tudi njihovo dokumentiranje in urejena ter hitro dostopna dokumentacija. V muzeju dokumentiranje premične dediščine obsega zbiranje, urejanje, hranjenje, interpretacijo in predstavljanje zbranih podatkov in dejstev o predmetih.

5 https://www.racunalniski-muzej.si/
Govorimo o več fazah, ki se začnejo z evidentiranjem predmeta (potencialnega predmeta za uvrstitev v muzejsko zbirko in zbiranjem podatkov za popis), ki mu sledi faza akcesije - zbiranje podatkov o pridobivanju (datumu pridobitve, lokaciji, lastniku, stanju na terenu).

Pridobitvi sledi popis predmeta. Standardni identifikacijski obrazec predmeta kulturne dediščine (Object ID) za popis zajema naslednja polja: inventarna številka, datum popisa, vrsta predmeta, material in tehnika, mere, napisi in oznake, posebnosti in značilnosti, naslov/ime predmeta, vsebina, čas/obdobje, izdelovalec/avtor, opis predmeta, kraj nastanka/ najdbe, fotografija/vizualni zapis predmeta. $Z$ nastajanjem t. i. dokumentacijskega obrazca o predmetu, govorimo o t. i. inventarizaciji predmeta. Z osnovnim inventarnim obrazcem je povezana vsa druga dokumentacija (evidenca, akcesija, obrazec o konservatorskih pregledih/posegih, vizualna dokumentacija (tekstovna, zvočna, filmska idr.), lokacija/hramba v depoju, in sekundarna dokumentacija (podatki o objavah, razstavah, dokumentacija o izposoji).

Skozi faze obdelave predmeta, v procesu muzealizacije predmet - muzealijo uvrstimo v muzejsko zbirko, s tem dobi status kulturnega spomenika. Gre za dinamičen proces, dokumentacija o predmetu se stalno dopolnjuje. Podatki so tudi osnova za izpis inventarne knjige predmetov kot temeljnega dokumenta muzejskih zbirk. Po načelih muzejske stroke dokumentiran digitalni artefakt lahko pridobi status muzealije in postane spomenik premične kulturne dediščine.

\subsection{Raziskovanje konteksta muzealije}

Pri raziskovanju širšega konteksta muzealije/v našem primeru digitalnih muzealij nas ne zanimajo le tehnične specifikacije računalniške opreme, temveč npr. tudi izkušnje razvijalcev opreme $\mathrm{v}$ danih družbenih razmerah, vloga odločevalcev - financerjev in naročnikov, ter končna uporabnost računalniške opreme ter implementacija na različnih ravneh, $\mathrm{v}$ gospodarstvu, javni upravi in zasebno, kaj je vplivalo na zaton razvoja slovenske računalniške industrije ipd.

$\mathrm{V}$ zadnjem času so lahko predmet raziskovanja vedno bolj aktualne razne oblike zasvojenosti $\mathrm{z}$ računalniško tehnologijo, socialna neenakost/razslojenost, ki jo povzroča (ne)dostopnost do svetovnega spleta, socialna vključenost in izključenost ipd. Za zbiranje podatkov in raziskovanje teh in podobnih 
tem v družboslovju uporabljamo specifične družboslovne raziskovalne metode dela, ki jih v nadaljevanju kratko opišemo [Flere, 2000, Ragin, 2007]: intervju, anketa, opazovanje.

- Intervju ali znanstveni pogovor je metoda zbiranja podatkov s pogovorno komunikacijo. Lahko je nestrukturiran: pogovor o določeni temi, sogovornika ne omejujemo $\mathrm{z}$ vnaprej določenimi vprašanji ali strukturiran: usmerjen pogovor po vprašalniku, zelo blizu anketi.

- Anketa je vnaprej pripravljen vprašalnik in možni odgovori, do katerih izprašanec izrazi svoja stališča.

- Opazovanje je lahko pasivno ali opazovanje z lastno udeležbo. Največkrat uporabimo intervju in opazovanje.

Sistematično opazovanje (določi se načrt in predmet raziskovanja) je metoda zbiranja podatkov, kjer dogodki potekajo po notranji logiki, opazovalec pasivno spremlja, opazuje in zapisuje potek dogajanja (lahko $\mathrm{z}$ avdio ali video snemanjem). Opazovanje $\mathrm{z}$ udeležbo je metoda zbiranja podatkov, kjer je opazovalec/raziskovalec aktivno vključen v proces dogajanja, ki ga raziskuje (stopnje udeležbe so lahko različne). Opazovanje in intervju omogočata predvsem kvalitativno analizo vsebine, strukturiran pogovor in anketa pa omogočata kvantitativno (statistično) analizo. Pogosto raziskujemo $\mathrm{z}$ dopolnjevanjem predstavljenih metod. Vsaka metoda ima prednosti in slabosti, razlikujejo se v zanesljivosti, preverljivosti in objektivnosti. Nekaj nestrukturiranih intervjujev s ključnimi osebami, ki so v preteklosti sodelovali pri nastajanju prvih slovenskih računalnikov, je bilo zbranih $\mathrm{v}$ okviru zgoraj omenjenega projekta SloRaDe.

Pri preučevanju fenomenov računalniške oz. digitalne dobe s pomočjo intervjujev (etnologi govorimo o ustnih virih), dobimo podatke in dejstva, ki pomembno dopolnjujejo pričevalnost predmetov. Dokumentarno vrednost imajo tudi spominski zapisi in memoarska literatura, npr. za raziskovanje razvoja slovenske računalniške industrije knjiga Hladna vojna in bitka za informacijsko tehnologijo [Škrubej, 2008]. Osnovni medij predstavljanja je v muzejih razstava, kjer muzealije in izsledke raziskav predstavimo zainteresirani in širši javnosti.

\section{OHRANITVENI VIDIKI EMULACIJE}

$\mathrm{V}$ tem delu predstavimo načine in oblike emulacije, ki so pomembni za digitalno ohranjanje. Na emulacijo se osredotočimo celovito, vključno z vidiki, ki so v literaturi mnogokrat zapostavljeni, npr. emulacija naprav in okolja.

\subsection{Emulacija}

Na področju digitalnega ohranjanja so prvotno prevladovali pristopi kot je npr. migracija. Pogled na uporabo emulacije $\mathrm{v}$ ta namen pa je bil obravnavan $\mathrm{s}$ skepticizmom, predvsem zaradi tehnične zahtevnosti in višjih začetnih stroškov [van der Hoeven et al., 2007]. Danes se emulacija obravnava kot enakovreden pristop, pomemben predvsem zaradi avtentične upodobitve zahtevnih digitalnih artefaktov brez zmanjšanja njihove integritete.

Emulacija je sicer precej širok pojem, ki ga v tem članku obravnavamo z vidika sistemske programske opreme [Smith and Nair, 2005], saj je naš glavni namen digitalno ohranjanje računalniških sistemov tako strojne kot programske opreme. S tega vidika je emulator programska oprema za nek računalniški sistem (gostitelj), ki oponaša delovanje (drugega) računalniškega sistema (gost). Njen glavni poudarek je na imitaciji obnašanja gosta, ki je na zunaj opazno, samo notranje stanje sistema pri tem ni pomembno. Namen emulatorja je, da se lahko uporabi kot nadomestek za izvorni emulirani sistem. Podobna ideja, osnovana na univerzalnem navideznem računalniku je opisana v [Lorie, 2001].

Pojem, ki je zelo soroden emulaciji, je simulacija, pri čemer je meja med obema pogosto zabrisana, zaradi česar je razlikovanje včasih težavno. Vseeno poskušajmo poudariti nekatere razlike med njima. Pri simulaciji gre običajno za oponašanje, ki temelji na modelu sistema, pri čemer je lahko omogočeno tudi opazovanje njegovega stanja - gre za notranje stanje simulatorja. Nadalje emulacija z natančnim oponašanjem poustvarja izvorno izkušnjo emuliranega sistema, ki ga je v okviru danega okolja praviloma moč uporabljati na način enakovreden izvorni uporabi. Primeri simulacije so simulator letenja, fizikalni simulatorji in simulatorji vremena. Dobro izvedeno (npr. realno-časovno) simulacijo lahko obravnavamo tudi kot emulacijo; v nadaljevanju članka bomo zato (kot je običajno na tem področju) govorili predvsem o emulaciji računalniškega sistema, četudi bo v ozadju morda simulacija. 
$\mathrm{V}$ praksi najdemo kopico emulatorjev računalniških sistemov. Pri tem mnogi poleg emulacije izbranih delov sistema zaradi razlogov učinkovitosti omogočajo tudi virtualizacijo, kjer gre za preslikavo vmesnikov in virov navideznega sistema v vmesnike in vire gostitelja. Sem sodijo emulatorji računalnikov, ki temeljijo na Intelovi x86 arhitekturi (npr. Bochs, QEMU, Virtual PC, VirtualBox), emulatorji hišnih oz. mini računalnikov kot so ZX Spectrum, Commodore 64, Atari 800XL in emulatorji retro igralnih konzol, kot je SEGA. Glavni namen teh emulatorjev je različen, gre pa pri emuliranju mini računalnikov in igralnih konzol, predvsem za digitalno ohranjenjanje računalniških iger in poistovetenje igralne izkušnje.

Obstajajo tudi emulatorji, npr. Dioscuri [van der Hoeven et al., 2007], ki so bili ustvarjeni neposredno za digitalno ohranjanje. Primer ohranjanja slovenskega starodobnega računalnika najdemo v [Horvat in Mihelič, 2018], kjer gre primarno za neposredno digitalno ohranjanje samega računalnika, ohranjanje samih pripadajočih digitalnih dokumentov je (lahko) sekundarnega pomena. Med najbolj pogosto uporabljanimi in popularnimi emulatorji najdemo predvsem emulatorje računalnikov in konzol, ki omogočajo prostočasne dejavnosti z igranjem retro računalniških iger. $S$ tem retro igre postanejo kulturni artefakt in izobraževalno orodje oz. nova živa umetnost [Carta, 2017].

Pri pristopu emulacija kot servis (EaaS) [von Suchodoletz et al., 2013] v igro vstopa ohranitvena ustanova (angl. memory institution), ki ponuja storitev emulacije. Pri tem uporabniku ni potrebno uporabljati specifičnih emulatorjev, ampak za dostop do storitve uporablja obstoječe spletne odjemalce. Celota lahko temelji na oblačnem računalništvu oz. porazdeljenem EaaS modelu, kjer gre za odmik od končnega uporabnika $\mathrm{k}$ specializiranim ponudnikom, pri čemer lahko slednji (knjižnice, arhivi, muzeji) dobijo novo poslovno priložnost $\mathrm{z}$ avtentično reprodukcijo digitalnih objektov in procesov.

\subsection{Nivoji emulacije}

Pri izvedbi emulacije se lahko osredotočimo na različne dele oz. nivoje računalniškega sistema [Guttenbrunner and Rauber, 2012]. Primer nivojskega pogleda na računalniški sistem je predstavljen na sliki 3. Strojna oprema, kot osnova računalniškega sistema, je pogosto predmet emulacije (primeri so navedeni $\mathrm{v}$ predhodnem razdelku), vendar to ni edina možnost.

Obstaja tudi več emulatorjev operacijskih siste- mov (primera sta emulatorja Wine in DOSBox), ki običajno preslikajo sistemske klice enega sistema $\mathrm{v}$ drugega. Celoten računalniški sistem pa vključuje tudi programsko opremo oz. aplikacije, katerih pogosto ne emuliramo v celoti, ampak izvedemo le en del (primer so pregledovalniki dokumentov, ki so bili ustvarjeni z neko drugo aplikacijo). Nadalje, pri celoviti izvedbi za izboljšanje uporabniške izkušnje emuliramo še okolje samega sistema in seveda tudi vmesnik med okoljem in sistemom, pri čemer gre pri slednjem za poistovetenje izvorne izkušnje uporabe vhodno-izhodnih naprav, npr. prilagoditev razmerij zaslonske slike ali poustvarjanje izvornih šumov in zvokov, ki jih oddajajo naprave.

\subsection{Notranji upogled}

Temelj emulacije računalnika je ustrezna tehnična izvedba navideznega stroja, ki oponaša delovanje izvorne arhitekture procesorja in pripadajoče strojne opreme. Pri tem gre predvsem za elemente, kot so procesor, registri, pomnilnik, strojni ukazi, vrste naslavljanja ipd. Osnovna izvedba izvajalnika navideznega stroja, torej komponenta emulatorja, ki izvaja ukaze gosta v okviru gostitelja, običajno temelji na tolmačenju. Naprednejša izvedba je možna s prevajanjem strojne kode gosta v ukaze, ki jih omogoča procesor gostitelja. Kadar sta si arhitekturi gosta in gostitelja podobni (npr. pripadata isti družini procesorjev), je ta način izredno učinkovit, saj gre pri prevajanju le za kopiranje ukazov. In nenazadnje, kadar sta si arhitekturi enaki in še nekaterih dodatnih pogojih [Popek and Goldberg, 1974], pa se gostovi ukazi lahko neposredno izvajajo na gostiteljevem procesorju. Podrobno obravnavo pristopov emulacije in virtualizacije najdemo v [Smith and Nair, 2005],

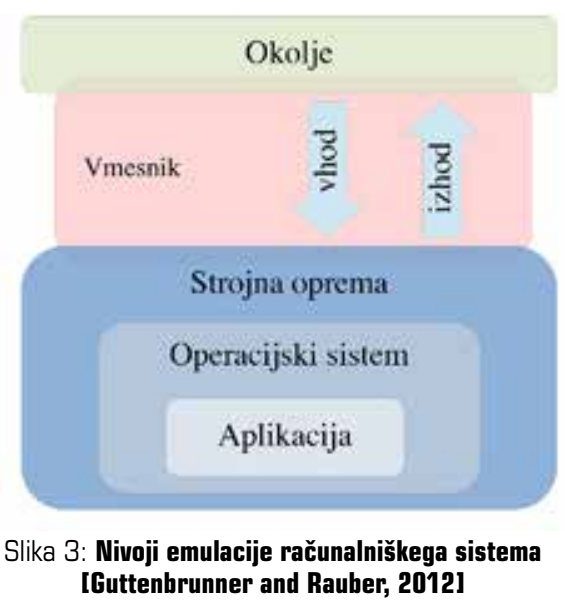


obravnavo računalniške arhitekture pa v [Hennessy and Patterson, 2003, Kodek, 2008]

Emulacija procesorja se običajno osredotoča le na programerju vidne lastnosti procesorja (registri, ukazi itd.). Izjemoma pa se emulirajo specifične značilnosti izvedbe samega procesorja (npr. časovno obnašanje signalov) ali pa nekatere nedokumentirane funkcionalnosti ipd.

Emulator lahko nudi funkcionalnost notranjega vpogleda, kar pomeni, da omogoča opazovanje ključnih elementov modela emuliranega sistema. Z opazovanjem modela, pa emulacija pravzaprav postane simulacija, kot smo opisali zgoraj. Primer grafičnega vmesnika emulatorja SicSim/SicTools [Mihelič in Dobravec, 2015], ki omogoča vpogled v stanje procesorja, je na sliki 4, kjer je prikazan vpogled $\mathrm{v}$ programsko vidne registre in strojni ukaz, ki se trenutno izvaja.

Poleg vpogleda v sistem nekateri emulatorji celo omogočajo tudi spreminjanje elementov emuliranega sistema. Obe funkciji, tako vpogled v stanje, kot njegovo spreminjanje, sta lahko koristni pri digitalnem ohranjanju računalniških sistemov. Dober primer tega je npr. ohranjanje starodobnih redkih računalnikov, kjer je dostop do izvorne strojne opreme in dokumentov težaven. Vpogled v notranje stanje emulatorja uporabniku tako omogoča lažje in hitrejše spoznavanje izvornega računalniškega sistema in njegove arhitekture, pozitivno pripomore lahko tudi $\mathrm{v}$ izobraževalnem procesu.

Večina emulatorjev žal ne nudi notranjega vpogleda, saj njihov glavni namen ni študija in ohranjanje samega računalnika, ampak predvsem zagotavljanje uporabnosti in dostopnost celotnega računalniškega sistema.

\subsection{Nadzor izvajanja}

Notranjemu vpogledu komplementaren del emulatorja je nadzornik izvajalnega stroja emulatorja. Sem

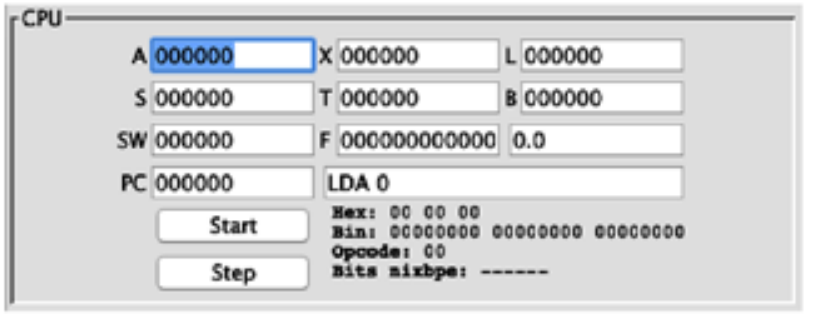

Slika 4: Primer grafičnega umesnika, ki omogoča upogled v stanje procesorja in nadzor nad izvajalnikom. sodijo predvsem osnovne funkcionalnosti, kot so zagon izvajalnika, prekinitev in nadaljevanje izvajanja ter izvajanje po korakih. Med napredne funkcionalnosti sodijo funkcije ustvarjanja slik izvajanja (angl. snapshot), hibernacija oz. shranjevanje celotnega stanja stroja na disk in obnavljanje stanja iz diska.

Poleg zgoraj naštetih funkcionalnosti pa so možne tudi statistične oz. računovodske funkcionalnosti. Primeri teh so prikazi različnih kazalnikov izvajanja, kot so grafični okvirji na sekundo, število prebranih in zapisanih bajtov, statistika vhodno-izhodnih dogodkov itd.

Omenimo še, da je pri samem izvajanju zelo pomembna tudi hitrost izvajanja ukazov. $\mathrm{V}$ ta namen obstaja več različnih tehnik izvedbe izvajalnega dela navideznega stroja [Smith and Nair, 2005]. V okviru nadzora izvajalnika pa imamo lahko na voljo tudi nastavitev hitrosti. Primer tega najdemo v SicTools emulatorju [Mihelič in Dobravec, 2015], ki je implementiran v programskem jeziku Java s pomočjo časovnika oz. razreda Timer. Največja natančnost oz. resolucija tega časovnika ni zadostna, zato lahko uporabimo preprosto tehniko izvedbe več ukazov pri vsakem proženju časovnika, da dosežemo zadovoljivo hitrost.

\subsection{Pomnilni mediji}

Pomemben vidik pri digitalnem ohranjanju računalniških sistemov je tudi obravnava pomnilnih medijev. Pogosto uporabljan pomnilni medij iz druge polovice dvajsetega stoletja je disketa, primer katere najdemo na sliki 2 a). Skozi zgodovino je bilo razvitih več vrst disket (npr. razlike v fizični velikosti) in še več formatov zapisa podatkov na njih. Tehnika digitalnega ohranjanja disket je izdelava njihovih bitnih slik.

Za branje disket potrebujemo posebno bralno-pisalno napravo oz. enoto, imenovano disketnik. Žal pa disketne enote, ki so bile v uporabi pri osebnih računalnikih, največkrat niso kompatibilne s starejšimi enotami drugih računalnikov. Poleg tega je magnetni zapis na disketah pogosto oslabljen zaradi zastaranosti. Posledično je izdelava bitnih slik lahko zelo zahtevno opravilo.

Pri digitalnem ohranjanju disket si lahko pomagamo z namenskimi bralniki, kot je npr. kryoflux naprava, ki je pravzaprav le prilagodljiv kontrolnik za klasično disketno enoto za osebni računalnik, katerega je moč konfigurirati na različne načine. Težave $\mathrm{s}$ formati razrešimo $\mathrm{z}$ ustreznim tehničnim znanjem (s področja obratnega inženirstva) in informacijami, 
žal pa so diskete še vedno lahko v slabem stanju in posledično neberljive.

Na manjših mini računalnikih pa so se namesto disket pogosto raje uporabljale takrat vseprisotne in cenejše audio kasete $\mathrm{z}$ magnetnim trakom. Primera dveh kaset z igrama za mini računalnik ZX Spectrum najdemo na sliki 5 . Osnovna različica omenjenega mini računalnika ni imela pripadajočega kasetnika, računalnik je podpiral preprosto povezavo kar z domačim hišnim kasetofonom. Ravno zaradi te raznolikosti vhodnih kasetnih naprav, je pri branju podatkov s kaset, pogosto potrebna fina nastavitev bralne glave kasetnika. Shranjevanje na kasete tako nudi več desetletno obstojnost podatkov.

Fizično kopijo kasete je možno preprosto izdelati s kasetofonom, ki vsebuje dve bralno/pisalni enoti ali pa preko povezave dveh kasetofonov; gre za enak postopek kot je kopiranje glasbe, saj so podatki na kasetah shranjeni v obliki različnih piskov. Seveda takšna kopija vsebuje tudi morebitne napake, ki so prisotne na izvorni kaseti.

Druga možnost je izdelava digitalne kopije. To lahko naredimo s posebnimi programi, ki so seveda navadno na voljo le za originalni računalnik. V takem primeru seveda pride prav ustrezen emulator. Spomnimo še na programe, ki so na kaseti zapisani v posebnem formatu, katerega namen je običajno hitrejše nalaganje programa s t.i. turbo nalagalniki. Programi za izdelavo digitalne kopije, običajno ne razpoznajo takšnih formatov.

Podobno kot $\mathrm{z}$ disketami je s trdimi diski. Potrebno je dobro poznavanje datotečnih sistemov tako $\mathrm{s}$ fizičnega kot z logičnega vidika. Vsi smo vajeni hierarhične datotečne organiziranosti, zato pogosto pozabljamo, da je nekoč lahko bilo drugače. Na primer, računalnik Partner ima tako 10 datotečnih področij za hranjenje datotek, brez hierarhične organiziranosti.

Pri delujočih starih računalnikih lahko do pomnilnih medijev dostopamo tudi neposredno, pri tem pa moramo paziti, da obstoječih podatkov ne prepišemo ali celo uničimo. Najbolje je tako čim prej izdelati bitne slike pomnilnih medijev ali naprav. Dobra in v praksi preizkušena tehnika (na računalniku Partner [Horvat in Mihelič, 2018]), uporabna za delujoče starodobne računalnike, je izdelava posebnega programa, ki neposredno prebere vgrajeni fizični disk in njegovo vsebino pošlje na nek vmesnik (npr. RS-232). $\mathrm{Na}$ ta vmesnik se povežemo s sodobnim računalnikom in prebrano vsebino shranimo v ustrezen so- doben format. Prednost te tehnike je, da kar najmanj posegamo $\mathrm{v}$ originalni sistem, in da je uporabna tudi v primeru (pogosto) nedelujočih disketnih enot.

\subsection{Prikazovalne naprave}

Prikazovalne naprave, ki vključujejo predvsem računalniške monitorje, so med najpomembnejšimi napravami $\mathrm{z}$ vidika digitalnega ohranjanja. Zraven sodijo še video kartice, katerih emulacija je ključna za uspešno celovito izvedbo. Pogosto emulatorji nudijo tudi možnost zajema zaslonske slike, kar je ena izmed pomembnejših funkcij digitalnega ohranjanja.

Starejši sistemi navadno temeljijo na tekstovnem prikazu. Pri tem je potrebno poistovetiti izvorno pisavo. Neposreden dostop do bralnega pomnilnika (ROM) kartice je mogoč s posebnimi elektronskimi bralnimi napravami in zahteva strokovno znanje, saj obstaja tudi nevarnost uničenja.

Drug nevsiljiv način je spet s pomočjo posebnega programa, ki zaporedoma izriše vse znake (v ustrezni povečavi), katere nato preprosto prerišemo (lahko ročno ali celo na nek bolj avtomatski način). Če računalnik podpira branje video pomnilnika, lahko znake kar od tam prepišemo v datoteko (in izvedemo njen prenos).

Pri emulaciji prikazovalnih naprav je težje simulirati njihovo notranje stanje, kot je npr. vrstično osveževanje starih zaslonov s katodno cevjo, zato včasih uberemo bližnjice, npr. sliko prikažemo kar na modernem zaslonu. Pri tem pa vseeno lahko emuliramo nekatere ostale značilnosti, kot je npr. svetlost zaslona, imitacija ogrevanja zaslona s katodno cevjo itd.

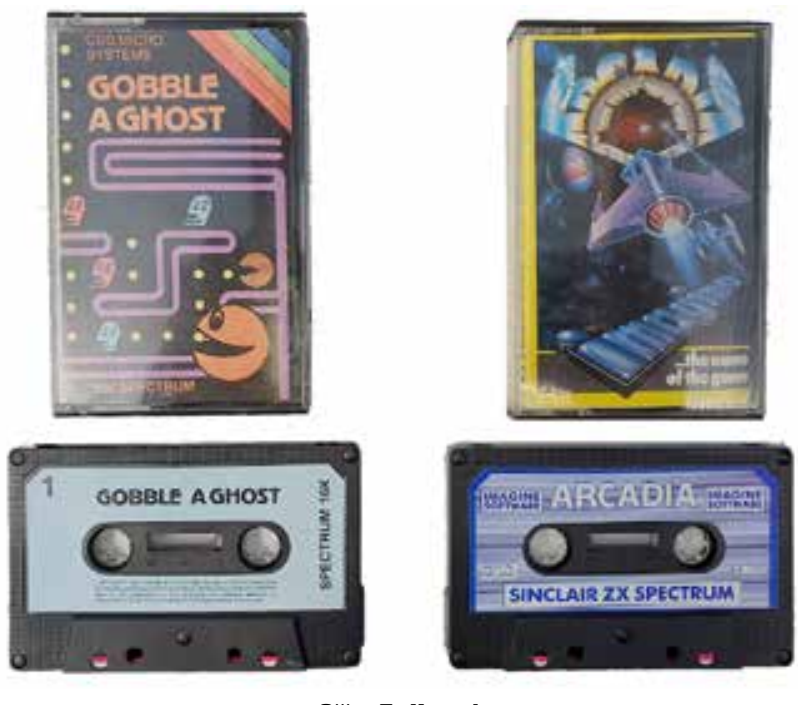

Slika 5: Kaseti 


\subsection{Ostale naprave}

Emulacija tipkovnice je nujen del praktično uporabnega emulatorja. Najbolj pogosta izvedba je z uporabo moderne tipkovnice, pri čemer je potrebno izvesti preslikavo bralnih kod tipk iz moderne na starodobno tipkovnico. Dodatno imajo nekatere starodobne tipkovnice različne signalne lučke, ki jih ni mogoče preslikati, lahko pa jih namesto tega prikažemo preko grafičnega uporabniškega vmesnika.

Oglejmo si še primer zanimive tehnike, ki je bila uporabljena pri izvedbi emulatroja za računalnik Dialog, za katerega nismo imeli na voljo originalne tipkovnice, zato je bil velik izziv, kako dobiti vpogled v sam sistem. Predlaganih rešitev je bilo več: od predelave obstoječih tipkovnic do emulacije originalne tipkovnice preko Arduino komponent. Končno izvedena rešitev je bila predelava nalagalne bitne slike operacijskega sistema, tako je sistem namesto s tipkovnice bral kode tipk iz serijskih vrat, kamor se je vzpostavilo povezavo s sodobnim računalnikom in ustreznim terminalskim programom.

Starodobni računalniki podpirajo tudi nekatere druge vhodno-izhodne naprave, kot so npr. zaporedna in vzporedna vrata, miška, grafična tablica in tiskalnik. Navadno gre za zelo specifične naprave in načine izvedbe, posledično izvedba zopet zahteva veliko strokovnega znanja, čeprav programsko največkrat ni zahtevna. Emulacija tiskalnika se pogosto izvede $\mathrm{s}$ tiskanjem $\mathrm{v}$ datoteko.

\subsection{Integracija $\mathbf{z}$ gostiteljem}

Pomemben in zanimiv vidik izvedbe emulacije, še posebej $\mathrm{v}$ kontekstu digitalnega ohranjanja, je integracija z gostiteljem. Integracija z gostiteljem omogoča preprost prenos podatkov od gosta do gostitelja in tudi v nasprotni smeri, pri čemer lahko izkorišča sodobne možnosti, ki jih nudi gostitelj.

Funkcionalnosti, ki sodijo v ta sklop, so npr. zajem zaslonskih slik, funkcionalnost odložišča, deljenje map ipd. Zajem zaslonskih slik lahko naredimo na dva načina: neposredno z branjem gostovega zaslonskega pomnilnika in ustrezne pretvorbe $\mathrm{v}$ sodoben slikovni zapis ali posredno preko gostiteljeve funkcionalnosti zajema slike, saj smo že za sam prikaz slike morali izvesti branje gostovega zaslonskega pomnilnika.

Izvedba odložišča in njegovih funkcionalnosti kopiranja, rezanja in lepljenja je še posebej zanimiva, saj starodobni sistemi teh funkcionalnosti ne podpirajo. Delna izvedba je vseeno mogoča, saj lahko kopiranja izvedemo z branjem zaslonskega pomnilnika, lepljenje pa s simuliranjem pritiskov tipk na emulirani tipkovnici.

\subsection{Emulacija okolja}

Za poistovetenje celostne izkušnje pri uporabi emulatorja je pomembna tudi pristnost oz. posnemanje izvornega okolja digitalnega artefakta. Starejši domači računalniki so kot prikazovalnik pogosto uporabljali zaslon na osnovi katodne cevi, ki potrebujejo nekaj sekund, da se ogrejejo in s tem dosežejo polno svetilnost. Učinek ogrevanja lahko preprosto imitiramo na sodobnih zaslonih, bolj zahtevno pa je posnemanje ukrivljenosti zaslona, prikaza slikovnih vrstic z ustrezno osveževalno frekenco ipd. K vzdušju pripomore tudi fotografija oz. slika izvornega artefakta, ki se npr. prikaže ob zagonu. Nekateri računalniki imajo poseben razpored ali pomen tipk, $v$ teh primerih koristi tudi slika originalne tipkovnice.

Dokaj preprosto lahko izvedemo tudi specifične zvoke, ki so jih oddajali starodobni računalniki, npr. brnenje ventilatorjev, zvok pritiska tipke, zvok vrtenja trdih diskov in premikanja njihovih bralno/pisalnih glav. Po naših izkušnjah emulacija okolja veliko prispeva k pristnosti uporabniške izkušnje, tako npr. emulator Partnerja imitira ogrevanje zaslona, zagon trdega diska, zvočno oglašanje s piskanjem in utripanje lučk tipkovnice [Horvat and Mihelič, 2018].

\subsection{Ostali vidiki}

Med ostalimi vidiki najprej omenimo ovrednotenje emulacije. Teorija in praksa takšnega ovrednotenja sta obširno predstavljeni v preglednem članku [Duretec et al., 2015]. Nadalje v članku [Guttenbrunner and Rauber, 2012] avtorji predstavijo ogrodje za ovrednotenje evaluacije s testi za določanje stopnje posnemanja lastnosti izvornega sistema.

Med manj tehnične, a še vedno pomembne vidike, sodijo še odgovori na pravna vprašanja, kot so npr. ali sploh lahko emuliramo ali izvajamo obratni inženiring danega sistema, ne da bi pri tem kršili avtorske pravice? Pri tem je treba upoštevati avtorske pravice tako nad samim sistemom, posameznimi komponentami kot nad nameščeno programsko opremo. Podatki emuliranih sistemov (npr. bitna slika izvornega trdega diska in drugih pomnilnih medijev) lahko vsebujejo tudi osebne in druge občutljive podatke. Pred objavo takšnih podatkov je tako treba izvesti vsaj anonimizacijo podatkov. 


\section{SKLEP}

V članku smo predstavili področje digitalnega ohranjanja, pri tem smo več pozornosti posvetili računalniški emulaciji, ki skupaj z muzejskim pristopom nudi celovito rešitev za ohranjanje digitalnih artefaktov. Večji del prispevka je posvečen opisu različnih vidikov računalniške emulacije, ki so uporabni za digitalno ohranjanje. Opis temelji na izkušnjah, pridobljenih s sodelovanjem $\mathrm{v}$ več različnih projektih digitalnega ohranjanja starodobnih računalnikov.

Emulatorja računalnikov Gorenje Dialog in IskraDelta Partner, na katerih temelji večina predstavljenih tehnik in izkušenj, sta (po našem vedenju) prva emulatorja slovenskih starodobnih računalnikov. Primerov takšnih računalnikov $\mathrm{v}$ slovenskem prostoru je še več, npr. IskraDelta Triglav, dela za prihodnost je tako še dovolj. Prav tako bi se obravnava lahko razširila na širši jugoslovanski prostor, katerega del smo nekoč Slovenci bili. Pri tem bi bilo nujno povezovanje $\mathrm{z}$ ustreznimi deležniki tega prostora.

\section{ZAHVALA}

Avtorja se zahvaljujeta udeležencem projekta Slovenska računalniška dediščina (Študentski inovativni projekti za družbeno korist), katerega rezultati so predstavljeni na https://jurem.github.io/SloRaDe/. Dodatna zahvala gre tudi Mateju Horvatu za razvoj in izvedbo emulatorjev.

\section{LITERATURA}

[1] [Bezek et al., 2012] Bezek, P., Ć osić, V., Rosina, D., Špetič, A., Vraničar, I., and Zornada, G. (2012). Goto 1982: razvoj računalniške kulture na Slovenskem. Ljubljana: Muzej novejše zgodovine Slovenije.

[2] [Bufon, 2018] Bufon, V. M. (2018). Iskra delta - od kotlovnice do industrijskega podjetja: Ob 40 . obletnici ustanovitve delte. Uporabna informatika, XXVI(4):153-159.

[3] [Carta, 2017] Carta, G. (2017). Metadata and video games emulation: an effective bond to achieve authentic preservation? Records Management Journal, 27(2).

[4] [Duretec et al., 2015] Duretec, K., Kulmukhametov, A., Rauber, A., and Becker, C. (2015). Benchmarks for digital preservation tools. In Proceedings of the 12th International Conference on Digital Preservation, Chapel Hill, North Carolina, USA.

[5] [Flere, 2000] Flere, S. (2000). Sociološka metodologija. Temelji družboslovnega raziskovanja. Maribor: Pedagoška fakulteta.

[6] [Guttenbrunner, 2007] Guttenbrunner, M. (2007). Digital preservation of console video games. [Guttenbrunner and Rauber, 2012] Guttenbrunner, M. and Rauber, A. (2012). A measurement framework for evaluating emulators for digital preservation. ACM Trans. Inf. Syst., 30(2).
[7] [Hennessy and Patterson, 2003] Hennessy, J. and Patterson, D. (2003). Computer Architecture - A Quantitative Approach. Morgan Kaufmann.

[8] [Horvat and Mihelič, 2018] Horvat, M. and Mihelič, J. (2018). Emulacija računalnika Iskra Delta Partner. Elektrotehniški vestnik, 85:185-191.

[9] [Knez, 2010] Knez, D. (2010). Fundus: razvoj in uporaba sistema za dokumentiranje zbirk oddelka za zgodovino in uporabno umetnost v NMS. In Zbornik 11. zborovanja Slovenskega muzejskega društva, pages 78-87.

[10] [Kodek, 2008] Kodek, D. (2008). Arhitektura in organizacija računalniških sistemov. Bi-tim.

[11] [Lorie, 2001] Lorie, R. A. (2001). Long term preservation of digital information. In Proceedings of the 1st ACM/IEEE-CS Joint Conference on Digital Libraries, JCDL '01, page 346-352, New York, NY, USA. Association for Computing Machinery.

[12] [Mihelič and Dobravec, 2015] Mihelič, J. and Dobravec, T. (2015). SicSim: A simulator of the educational SIC/XE computer for a system-software course. Computer Applications in Engineering Education, 23:137- 146.

[13] [Ministrstvo za kulturo Republike Slovenije, 2013] Ministrstvo za kulturo Republike Slovenije (2013). Smernice za zajem, dolgotrajno ohranjanje in dostop do vsebin kulturne dediščine $v$ digitalni obliki.

[14] [Online Computer Library Center, 2006] Online Computer Library Center, I. (2006). OCLC Digital Archive Preservation Policy and Supporting Documentation.

[15] [Popek and Goldberg, 1974] Popek, G. J. and Goldberg, R. P. (1974). Formal requirements for virtualizable third generation architectures. Commun. ACM, 17(7):412-421.

[16] [Ragin, 2007] Ragin, C. C. (2007). Družboslovno raziskovanje. Enotnost in raznolikost metode. Ljubljana: Fakulteta za družbene vede.

[17] [Simikič, 2002] Simikič, A. (2002). Dokumentacijski sistem v Slovenskem etnografskem muzeju. Etnolog, 12(1):317-326.

[18] [Smith and Nair, 2005] Smith, J. E. and Nair, R. (2005). Virtual Machines: Versatile Platforms for Systems and Processes. Morgan Kaufmann.

[19] [Strodl et al., 2007] Strodl, S., Becker, C., Neumayer, R., and Rauber, A. (2007). How to choose a digital preservation strategy: Evaluating a preservation planning procedure. In Proceedings of the 7th ACM/IEEE- CS Joint Conference on Digital Libraries, JCDL '07, page 29-38, New York, NY, USA. Association for Computing Machinery.

[20] [van der Hoeven et al., 2007] van der Hoeven, J., Lohman, B., and Verdegem, R. (2007). Emulation for digital preservation in practice: The results. The International Journal of Digital Curation, 2(2):123-132.

[21] [von Suchodoletz et al., 2013] von Suchodoletz, D., Rechert, K., and Valizada, I. (2013). Towards emulation- as-a-service: Cloud services for versatile digital object access. The International Journal of Digital Curation, 8(1):131-142.

[22] [Webb, 2003] Webb, C. (2003). Guidelines for the preservation of the digital heritage.

[23] [Škrubej, 2008] Škrubej, J. (2008). Hladna vojna in bitka za informacijsko tehnologijo. Pasadena. 
Jurij Mihelič je leta 2006 doktoriral iz raǒnalniških znanosti na Fakulteti za raǒnalništvo in informatiko Univerze v Ljubljani, kjer trenutno pouăje kot docent. Njegova raziskovalna podrọ̆ vsebujejo inženiring algoritmov, sistemsko programsko opremo, operacijske sisteme, izvajalna okolja in programske jezike.

Mojca Ferle je leta 1989 diplomirala na Filozofski fakulteti Univerze v Ljubljani iz etnologije in sociologije kulture. Od leta 1991 je zaposlena v Mestnem muzeju Ljubljana, Muzeju in galerijah mesta Ljubljane kot kustodinja za urbano etnologijo in skrbnica zbirke za tekstil, leta 2016 je pridobila naziv muzejska svetnica. Poleg zanimanja za etnologijo meščanstva večkrat sodeluje v delovnih skupinah za muzejsko dokumentacijo in terminologijo; sodelovala je tudi kot delovna mentorica pri študentskih projektih FRI. 